\title{
The Difficult Case Consultation: An intervention for interprofessional health communication
}

\author{
Elissa Foster, Jay Baglia \\ Health Communication, College of Communication, DePaul University, Chicago, USA
}

\begin{abstract}
An interprofessional group of healthcare practitioners sought a new approach to the early detection, prevention, and resolution of "difficult cases" in the inpatient care context. An action research project addressed this need by developing a narrative re-framing tool that helped reveal entrenched assumptions regarding the root causes of difficult cases in the hospital. The intervention method that emerged from the project - the Difficult Case Consultation (DCC) - is a theoretically-grounded process that helps teams to analyze and address complex communication problems in interprofessional healthcare contexts. Collaborative processes grounded in theory have proven to be the most successful when seeking to optimize healthcare team communication. The article describes the collaborative development of the DCC, presents two cases illustrating the process, and describes systemic factors that exacerbated the emergence of difficult cases in the inpatient context.
\end{abstract}

\section{Introduction}

A distinguishing feature of applied health communication scholarship is its capacity to intervene and make a positive difference in response to "real life" problems. ${ }^{1}$ When we were invited to participate in one healthcare network's interprofessional task force to address the

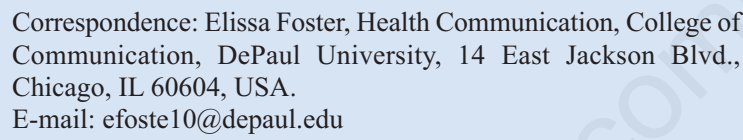

Key words: Action research; health communication; interdisciplinary health team; medical error; root cause analysis.

Acknowledgements: The authors wish to acknowledge Lou Lukas, $\mathrm{MD}$, for her leadership of the original interdisciplinary working group; and Krista Hirschmann, PhD for her insights during the early stages of the project.

Availability of data and materials: Primary source materials analyzed during this study are not publicly available.

Ethics approval and consent to participate: Not applicable.

Informed consent: Not applicable.

Received for publication: 15 July 2021.

Revision received: 1 January 2022.

Accepted for publication: 3 January 2022.

This work is licensed under a Creative Commons Attribution NonCommercial 4.0 License (CC BY-NC 4.0).

${ }^{\circ}$ Copyright: the Author(s), 2021

Licensee PAGEPress, Italy

Qualitative Research in Medicine \& Healthcare 2021; 5:9977

doi:10.4081/qrmh.2021.9977 issue of difficult cases in the inpatient setting, we saw an opportunity to improve outcomes for patients, healthcare practitioners, and the organization. In brief, we came to understand difficult cases as those that i) include lengthy and/or costly hospital stays, ii) lead to poor or unanticipated outcomes, and iii) include complex communication among multiple stakeholders. This article presents a definition of difficult cases that distinguishes them from medical error, describes the development of the Difficult Case Consultation (DCC) process including its format, and offers outcomes from a preliminary review of the intervention by clinical staff at the hospital.

Our project reflects the goals and practices of action research, which demands close collaboration between researchers and professionals to improve healthcare practice. ${ }^{2,3}$ Our approach also owes much to the field of organizational rhetoric, which analyzes the nature of organizational life through the persuasive practices of language. Foundational articles by $\mathrm{Cheney}^{4}$ and $\mathrm{Crable}^{5}$ established the applied nature of organizational rhetoric, arguing that insights into the pragmatic workings of an organization can be accessed via the study of its symbols, whether physical, behavioral, or verbal. The DCC is a facilitated, collaborative, and structured process in which members of an interdisciplinary clinical team i) recount the story of a difficult case (ideally, while it is in progress), ii) analyze the narrative elements of the story, and iii) reframe and retell the story using a different set of narrative assumptions. The point of this narrative reframing is to move the team members' perceptions of agency from the patient or family to the healthcare organization and its workers, including the team members. Because the DCC interrogates how the language of particular teams both enables and constrains their clinical decision-making and actions when dealing with problems or "issues," our investigation is methodologi- 
cally aligned with both applied health communication and organizational rhetoric. ${ }^{6}$

The goals of the project were: i) to operationalize the concept of "difficult cases" from the perspective of the participants; ii) to highlight the role of the healthcare system (and not merely individual actors) in difficult cases; iii) to develop and test a reproducible group process (eventually named the "Difficult Case Consultation"); and iv) to gather feedback from health care practitioners regarding the utility of the DCC to their clinical work.

As we came to understand and define them, difficult cases are those that can involve a lengthier than expected hospitalization, poor outcomes for the patient, and high levels of stress for healthcare team members and patients' families. However they play out, difficult cases always impinge upon a system of finite resources-financial, physical, and emotional-for patients, family members, and healthcare providers and require engagement in multiple complex and difficult conversations. Like "never events" that are indicators of poor quality health care, the difficult case may be easily recognized in retrospect as something to avoid. However, "never events" such as wrong-side surgeries or incompatibility of blood type in transfusions are, by definition, rare and preventable, whereas the difficult cases we encountered seemed both inevitable and extremely difficult to control once in play. One reason for this seeming inevitability was that the origins or predictors of the difficult case were not as easy to identify as a procedural or diagnostic error. At the same time, most practitioners involved in the difficult cases we reviewed reported experiencing a "gut instinct" that a case was not going to proceed or end well. Part of the challenge of responding to the difficult case, therefore, involves team members being willing and able to voice concerns early enough in a patient's care to prevent exacerbation of a problematic situation and subsequent downward spiral.

In this report, we first present the background of the project including the macro and mezzo dimensions that impact difficult cases and the theoretical frameworks we employed in designing the intervention. We then describe the evolution and testing of the DCC process over the course of five meetings with an interprofessional team of eleven health practitioners; our description of these five meetings summarizes what was an emergent, collaborative, and iterative series of conversations from which the DCC reframing process emerged. We then illustrate the narrative reframing at the heart of the DCC process by summarizing two exemplar cases, presenting each case as it would typically be conveyed in a clinical setting and as it was told after DCC reframing. We present the preliminary assessment of the DCC as it occurred at a meeting of approximately 100 employees of the hospital, and we conclude with a discussion of the DCC as a communication-based intervention along with our intended next steps.

\section{Background}

\section{National context (the macro level)}

Many factors contribute to the complexity of difficult cases, including the aging of the population, ${ }^{8}$ the rising incidence of chronic and complex illness including obesity and diabetes, ${ }^{9}$ the ballooning costs of health care due to a dysfunctional system, the negative impact of the medical hierarchy on communication and collaboration across professional boundaries, ${ }^{10,11}$ and the implementation of the $\mathrm{Pa}$ tient Portability and Affordable Care Act with its attendant calls for greater accountability, quality, and teamwork in the delivery of care. ${ }^{12}$ In addition, the construct of "health care quality" is multidimensional and not understood in the same ways by patients and healthcare practitioners or administrators. Poor documentation, contraindications of pharmaceuticals, problematic communication practices among interdisciplinary staff members, as well as inadequate nurse-to-patient ratios all threaten optimal patient care and outcomes. Patient actions and a lack of agreement among family members about courses of treatment can also add challenges to already complex systems of care.

Interprofessional teamwork in the health context has gained considerable interest among practitioners, administrators, and researchers in the last two decades. In a systematic review of the research, Schot et al. ${ }^{11}$ describe how healthcare professionals bridge gaps based on disciplinary differences using communication, negotiate overlaps in care responsibilities based on clinical processes, and create opportunities for collaboration by establishing physical space and adjusting professional practices. Distinct professional cultures bring about many of the challenges to successful collaboration among team members who have different training, values, and norms of communicating. Furthermore, these socialized differences often result in power imbalances with regard to team members and their ability and willingness to contribute perspectives. ${ }^{12}$ Nevertheless, meta-analyses have demonstrated how healthcare teams can be effective as well as challenging. ${ }^{13}$ In this project, we recognized interprofessional communication in teams as both the cause of and the potential solution to difficult cases.

Difficult cases are not necessarily associated with medical error, but the framing of medical error and communication practices surrounding them offer a worthwhile point of comparison. Also known as "iatrogenesis," "adverse effects," "nosocomial infection", and, less directly, "complications," 14 medical errors are often associated with novice clinicians, untested procedures, and complex care. In the United States alone, medical errors are estimated to result in as many as 250,000 unnecessary deaths ${ }^{15}$ and over one million excess injuries each year. Unlike medical error because there are no standard definitions or characteristics that would mark a case as "difficult," there are no statistics to identify how prevalent the phenomenon may be. 
Historically, the healthcare industry's primary efforts to minimize errors have involved penalizing - via suspension, demotion, or termination - those directly responsible for mistakes. The penalty approach typically included new rules or procedures intended to prevent the same mistake from happening again, but did not necessarily prevent similar mistakes. In contrast, root cause analysis ${ }^{16-18}$ assumes that solutions to problems are best discovered by identifying and eliminating the origins of error, minimizing problem recurrence. Because a single intervention is unlikely to completely prevent recurrence of error, root cause analysis is designed to be an iterative and ongoing process. Concluding a systematic review of root-cause analysis as an interventional process, Martin-Delgado et al. ${ }^{19}$ recommend that future research prioritize the problem of how to best translate the results of root cause analysis into practice improvements. Trust issues and deeply flawed communication practices also contribute to poor outcomes for patients and hospitals. ${ }^{20}$

The wider context of health care quality and medical error, including successful approaches to addressing medical errors such as root cause analysis, contributed several key principles as we designed an intervention into difficult cases. First, we determined that the intervention must incorporate an understanding of complex causes and the role of systems (rather than individuals) in creating the conditions for the difficult case. Second, we intended the intervention to target persistent cultural assumptions and practices within a given context in order to broaden its impact. Third, we anticipated that intervention should be employed as an iterative process that could be revisited as the system identifies and responds to emergent difficult cases.

\section{Organizational context (the mezzo level)}

In response to an identified need for collaboration across clinical units of the healthcare network, we (the authors) joined an interprofessional team of hospital staff to explore the reasons and the possible solutions for difficult cases. The group was convened by a physician leader in the palliative care branch of the hospital, with the intention of finding and resolving difficult cases as early as possible to avoid poor outcomes and squandered resources. Although the network had experienced no sentinel events, ${ }^{21}$ a culture of reflection and improvement had been established through a number of initiatives; these included Schwartz Rounds $^{22}$ - a structured forum in which healthcare practitioners from across the hospital network gather to discuss patient cases that spark emotional responses and call for collective sense-making - and TeamSTEPPS - developed by the Agency for Healthcare Research and Quality to guide effective teamwork to support patient safety. Consequently, the organizational culture was well positioned to initiate a project in response to cases that seemed easy to recognize in hindsight, but difficult to anticipate or redirect as they unfolded. Although not all of the following objectives were achieved, at the time the group was convened, the following activities were proposed: i) defining what constitutes a "difficult case;" ii) identifying the medical, legal, educational, personal, and systemic issues associated with difficult cases; iii) creating a multi-stage process for identifying and resolving difficult cases; iv) developing a plan to educate staff about the process; $v$ ) defining outcome measures; and vi) monitoring the impact of the new process over time.

The core group was comprised of seven physicians from a range of specialties, one ethicist, two nurse managers, one case manager, and two health communication scholars (the authors) who served to facilitate the process as well as to provide insight into the possible communication implications of the difficult cases.

\section{Theoretical frameworks}

Early in the process, we adopted a narrative-based methodology in order to better understand the communicative and relational dynamics involved in difficult cases. Narrative and medicine have a robust history that includes narrative-based clinical practices, ${ }^{23}$ narratives of patients' experiences ${ }^{24}$ and personal narratives of physicians $.^{25} \mathrm{Nar}-$ rative can also be employed as an analytical tool to reveal meaningful characteristics of stories. An important assumption that underlies narrative analysis is that the story of any given event - even the seemingly objective clinical case account — can be told in myriad ways depending on the perspective and motives of the teller. Narrative analysis, then, is a systematic method of exploring rhetorical choices (such as literary devices) along with how the characters, scenes, time, and plot are expressed. ${ }^{26}$ One approach familiar to scholars of rhetoric is the dramatistic pentad. ${ }^{27}$ Dramatistic analysis involves identifying five elements in a given narrative: the agent, act, scene, purpose, and agency. By undertaking a dramatistic analysis and identifying the relative weight given to each of these five elements, it is possible to identify the implicit or explicit motives of the storyteller. These elements of the pentad are similar to the journalist's toolkit: the who (agent), what (act), where and when (scene), why (purpose), and how (agency) of a news story. Burkean analysis has been employed in other health contexts, such as use of spatial metaphors in stories by patients with $\mathrm{HIV}^{28}$ and facilitator responses to relationship-centered care curriculum. ${ }^{29}$

Given that there are many ways to recount the story or drama of an event, applying narrative analysis to an organizational story can provide information about organizational life by identifying how a story (its characters and their motives, the scenes, and action) is described. By narratively analyzing the "facts" of an organizational story, we can reveal both conscious and unconscious choices about how organizational members make sense of a situation. By asking how else this story might be told, we can reveal opportunities for meaning and action that may not have been available under previously accepted, objective "facts." Research has shown the usefulness of examining how interprofessional teams discursively frame various 
elements of their work; for example, McDougall and colleagues ${ }^{30}$ demonstrate how cardiologists and nephrologists frame fluid management differently. Goffman ${ }^{31}$ points out that frames enable entities to share common ground through language and experience and that frames create limitations when they foreclose the perception of alternate possibilities.

In the section that follows, we describe the development of the DCC including the facilitation process that emerged as we pursued the goal of identifying difficult cases and their specific features, including dynamics related to interprofessional team communication. In the Results section, we illustrate the DCC process and impact of narrative reframing with two composite cases, and in the Discussion, we offer implications and outcomes of this project both for the context in which it occurred and as a transferable process.

\section{Method: Development of the Difficult Case Consultation Process}

\section{Researchers' roles}

Our perspective and function within the interdisciplinary group was complex. At the time of the meetings, we were both "insiders" (as employees of the hospital) and as non-clinicians on a team comprised mostly of physicians - also brought an "outsider" perspective to the process. Further, we facilitated these meetings and were invited to contribute to the process of case analysis by providing communication expertise when needed. We independently recorded observational notes during the meetings and met to discuss meeting outcomes after each session. Thus, we functioned as full participants in the process. ${ }^{32}$

\section{Ethics and internal review}

The activities of the interprofessional task force fell under the category of a quality improvement (or QI) project, which made them exempt from review by the hospital Institutional Review Board. Nevertheless, we obtained permission from the participants to i) record process notes, ii) collect the group members' notes and cases that were discussed at the meetings, and iii) write an account of the process that could be submitted for publication. Mindful of patient and family privacy, the group agreed to de-identify all cases both during verbal presentation and in notes given to us. We recognized that it would be essential to provide specific examples of cases to convey our process to the reader, so, as an added privacy measure for task force members and patients, we developed composite cases $^{33}$ to illustrate our results.

\section{Facilitation}

During the developmental phase of the project, the interdisciplinary team of eleven health professionals and two facilitators met a total of five times (one hour every one to two weeks) with minimal "homework" between meetings.

\section{Meeting 1: Defining the Difficult Case}

We asked each member of the task force to take three minutes to contribute a case identified as "difficult" by virtue of the basic features outlined earlier: a lengthier than expected hospitalization, poor outcomes for the patient (and family members), and/or high level of stress for healthcare team members. Some of these cases had lasted for many months and had multiple complicating factors and events. Even so, every team member was challenged to present their story in three minutes or less, in order to draw out what was most essential to the drama of the case. These stories followed accepted format for clinical case presentations, beginning with identifying information about the patient and the chief complaint (e.g., 81 year old male with acute post-operative delirium and failure to recover), relevant history (former smoker who survived an emergency repair to a ruptured aortic aneurysm), physical findings (loss of coordination, loss of bladder and bowel control, refusal to eat, blood albumin below critical level), and clinical plan (e.g., consultations with psychiatry, registered dietician, physical therapy, and occupational therapy). Because these were past cases, the classic case presentation concluded with a summary of the impact of the case and the patient's outcome (e.g., family distress extremely high, extended stay in the cardiac recovery unit unable to transfer to rehabilitation, patient developed an infection, returned to the ICU, and did not recover).

Using a worksheet, we asked each presenter to employ the journalist's tools by determining the who (corresponding to Burke's agent), what (act), where and when (scene), why (purpose), and how (agency) of their individual cases. Upon review, without exception and according to standard practices of clinical case presentation, when assigning the "who/agent" of the case, every presenter chose the patient. Subsequently, the "what/act" described the course of the disease and therapeutic intervention. The "where and when/scene" was the hospital unit or service caring for the patient. The "why/purpose" and "how/agency" of the case laid out various complications of the disease, difficulties of treatment, conflicts among specialists, hospitalists, and primary care physicians, and/or psychopathologies of the patient or members of the family. During this initial meeting, as a whole group, we reviewed three of the eleven team members' cases using the five Ws corresponding with Burke's pentad before introducing the idea of narrative reframing. In the case outlined in the previous paragraph, this would read as follows: who (81 year old male former smoker), what (failing to recover from surgical repair to a ruptured aortic aneurysm), where and when (in the cardiac recovery unit of the hospital); why and how (patient's refusal to eat, prolonged delirium, distressed family members, possible underlying psychiatric problems). 


\section{Meeting 2: Reframing the Difficult Case}

During this second meeting, we invited the participants to take one of the cases from the first meeting and reconfigure its original (customary) framing by reassigning the patient from "who/agent" to "where and when/scene" and reassigning the healthcare system from "where and when" to "who/agent." The retelling of the case - that is, how the members of the team conveyed the story - was strikingly different in the reframed version, especially with regard to the how and why the case was difficult. We present two summary illustrations of this before-and-after effect in the Results section, and it is important to note that during these initial meetings, the participants sometimes found it challenging to complete the reframing of the cases with the system in the position of "agent." Our decision to make the healthcare providers and system the "who/agent" of the story and patients the "where and when/scene" in no way reflects a devaluing of the patient's significance or agency in these cases. Rather, for the clinical participants in the DCC, this reframing exercise was intended to reveal their (often unacknowledged) influence and power so that they could perceive the roles that they and the system of care played in the outcomes of these difficult cases.

\section{Meeting 3: Practicing the analysis}

Having successfully worked through the reframing of the case once, it was important to replicate the process with a different case to see if it would produce similarly meaningful results. To that end, the group collaboratively selected and analyzed a second case from the set presented at the first meeting, beginning with the original framing of the patient as "who/agent" and then reframing with the system as the "who/agent." The group noted how the reframing allowed them to see actions and communication of the hospital system and its members that had contributed to the difficulty and intractability of the case.

\section{Meeting 4: Internal assessment}

In an effort to further assess the reliability of the process, we (i) selected another case from the set that was presented during the first meeting, (ii) split the team into two groups that engaged the narrative reframing process independently, and (iii) engages in a whole-group discussion to compare the two sub-groups' results to see whether similar conclusions were reached regarding the systemic motives and factors of the case. The interdisciplinary team worked through four more cases in this way-having two groups independently reframe each case and then compare results - before determining that the independent analyses resulted in substantial agreement between the groups' reframed narratives. Whereas it had taken a whole meeting to reframe the initial cases, during this meeting, it became clear that, with practice, the team was able to review and reframe cases relatively quickly using the DCC frame- work. At the end of this meeting, we also recognized that a certain degree of saturation had been reached regarding the systemic factors in the "difficult cases;" that is, the same observations about the system began to be repeated. At this point, the group agreed that we had enough material to address the initial objectives of the task force.

\section{Meeting 5: Solidifying the intervention}

The group reviewed its progress, synthesized and verbally summarized the impact of the DCC analysis process on the group's thinking, and established goals for a system-wide resolution process based on the narrative reframing process of the DCC. Although network priorities shifted and we were not able to create the imagined identification and resolution process, the team agreed that the DCC reframing was an important technique for helping clinicians to review and discuss difficult cases in a new light and, in our experience, to collaboratively identify avenues for positive change.

\section{Results: The reframed cases and preliminary review of the DCC}

From the cases that were presented in the course of this intervention, we determined that difficult cases in the given inpatient setting occurred when: i) the prescribed treatment options seem futile to many of those providing care, ii) healthcare surrogates (often family members) behaved in ways the clinicians did not understand or support, iii) resources employed seemed to exceed plausible benefit to the patient, and/or iv) staff distress in coping with the case was high. Sometimes, the hospital ethics committee and/or inpatient case manager could be effective at bringing these cases to acceptable conclusions, but when those consultations failed to result in any meaningful progress, the cases persisted to the frustration of patients, family members, and hospital personnel alike.

In this section, we offer two examples of difficult cases - first as they would typically be presented to the group at the beginning of a DCC process and then as they would appear after engaging in narrative reframing via the DCC. As described briefly in the Methods section, the "before" cases bear a strong resemblance to the typical clinical case presentation and follow a motive of describing and justifying clinical decisions; the "after" cases convey quite a different narrative and follow a motive of illuminating the role or agency of the system in the action that unfolded. At the conclusion of this project, we anticipate that other interdisciplinary teams, with appropriate facilitation, could accomplish the DCC narrative reframing of a case in the course of a single one-hour meeting, with a majority of that time spent reflecting on the implications of the reframed narrative.

Although names of patients, family members, and providers were never discussed in the meetings so as to 
protect patient and family confidentiality, we have also altered a number of facts about each of these cases while preserving an account of the dynamics of the case from the perspectives of the participants. Thus we (the authors) constructed these accounts - both the "original" cases and the reframed narratives - for illustrative purposes from the process notes we recorded at the time and from worksheets completed by the participants.

For the interdisciplinary team, the power of the DCC reframing lay not so much in the transformation of the facts as it did in the group's collaboration to dismantle existing assumptions and prejudices in order to rewrite the stories. As we discuss later in this article, presenting cases with a focus on patients and their diseases is an accepted practice that marks clinical objectivity and also obscures important, systemic factors in a patient's care. By working together to perceive and narratively construct a familiar clinical story in an unfamiliar way, the participants in the DCC were able to perceive and then question the assumptions that motivated clinicians' actions and contributed to the difficulty of the case. In guiding the team to uncover their assumptions and critique past actions together, through structured analysis and without blame, the DCC process was cast in the light of discovery rather than culpability. The example cases are offered here as an illustration of the transformation of facts into possibilities for improved communication and patient outcomes.

\section{Case 1: The problem patient}

As first described, this case focused on the behavior and actions of a "non-compliant" patient and "enabling" family members and was presented by a participant during the first meeting in the following general terms.

A morbidly obese female in her thirties was hospitalized for treatment of a large decubitus ulcer on her thigh and buttocks, which developed from remaining immobile on a couch for several months following a fall. The treatment of the ulcer was medically complex involving a physician of record from Plastics [reconstructive or restorative surgery, sometimes cosmetic], and consults from Internal Medicine and Psychiatry who deemed the patient to be competent. The patient, however, was not compliant with care plans; for example, she refused to engage in physical therapy or to sit up to eat. The patient was hospitalized for many months with no discernible progress toward being able to discharge to home. The family members, including a sister who was an attorney, refused to support hospital staff in gaining the patient's compliance and, at one point, consulted an orthopedist from outside the hospital network. Hospital staff consulted both risk management [their own attorneys] and the ethics team in efforts to resolve conflict. Communication among the hospital staff, patient, and family was often at cross-purposes regarding goals of treatment. Simultaneously, hospital staff accused family members of enabling the patient and, furthermore, of craving attention and feeding the conflict.

After DCC reframing, this case was recast as follows.

Hospital staff from Plastics, Internal Medicine, Psychiatry, the medical-surgical floor, Physical Therapy, Ethics, and Risk Management undertook care of a morbidly obese patient in her thirties suffering from a large decubitus ulcer. Over the course of many months, this assembly of medical professionals was unsuccessful in developing and communicating an overall care strategy, which resulted in fragmentation of daily tasks for nursing and physical therapy. Medical staffing of the hospital, which dictated that attending physicians supervised the case for one week at a time, led to the patient and family perceiving no continuity of care over the course of the hospitalization, and the medical leadership in this case was unclear to them. Further, hospital staff could not communicate a unified plan to the patient and family members, which led to an increasing sense of alienation between members of staff and the patient and family. The lack of coordination among the hospital staff, as well as the regularly-shifting care plans, were likely a product of short-term efforts to appease the patient and family in order to "make everybody happy," as well as a reluctance among the hospital staff to actively address their competing interests-for example, the different goals and approaches of the medical and nursing staff compared to the advice given by risk management.

\section{Case 2: A tragic end}

This case described the death of a hospitalized patient who had received a late-stage cancer diagnosis. In its initial form, the case focused on a deeply regrettable, but seemingly inevitable, sequence of events.

A 48-year-old male presented in the emergency room with shortness of breath and was diagnosed by the attending of record - a family medicine physician - with Stage IV cancer that had metastasized to the lungs. Upon receiving the terminal diagnosis and a prognosis of only a few weeks to live, the patient stated that he wanted to go home to be with his wife and two teenaged children. Because of the cancer diagnosis, an oncologist was consulted who disagreed with the initial prognosis given by the family physician and "took over" the case, suggesting that the patient could live for 5 to 10 years if radical treatment was successful. The palliative medicine team was also consulted; they 
agreed with the prognosis given by the family physician but, for the patient, an element of mistrust had emerged due to the conflicting prognoses from the different physicians. Ultimately, the patient agreed to undergo "heroic measures" in an effort to survive. Despite the misgivings of the family physician (whom the patient had designated as primary care provider because he had no existing relationship with a $\mathrm{PCP}$ ) and the palliative care team, the patient was admitted to the hospital for surgery from the ER. Within 10 days, the patient died while undergoing his second surgery having never returned home from that initial visit to the ER for shortness of breath.

After engaging in a challenging and complex DCC process, the case was reframed:

The diagnosing family medicine physician (later designated as the patient's PCP), the consulting members of the palliative medicine team, and the oncologist were called to care for a 48-year-old father who came to the emergency department with distressing symptoms that led to a devastating diagnosis. The patient expressed a clear set of priorities when given the prognosis of only weeks to live. Specifically, he wanted to return home and spend time with his family. The physicians in the case failed to communicate their various perspectives effectively to one another. The oncologist "took over" the case once he was consulted and the designated family physician/PCP and palliative medicine team members were unwilling to "overrule" the specialist; they also did not recommend a second oncology consultation. In this case, the assumed medical hierarchy - in which there was a disempowering relationship between the PCP and specialist-obscured the expressed desire of the patient to die at home. The oncologist's desire was to "give the patient a chance to live" and so he "did everything" he could to achieve the patient's survival. The perspective of the PCP and palliative medicine team was that a distorted sense of professionalism prevented them from contradicting another physician when they believed that the patient was being given false hope - a hope that put at risk and ultimately robbed him of his ability to be at home with family in his final days.

The pentadic elements from these two cases are summarized in Table 1.

\section{Difficult Case Consultation preliminary review}

The culmination of the interdisciplinary group's work on the DCC process was a presentation at the hospital's
Schwartz Center Rounds - a monthly meeting open to all members of the hospital and dedicated to conversations about the emotional difficulties of complex care or loss of life..$^{34}$ The physician leader of the DCC, one of the nurse managers from the group, and the second author requested to present the process at Schwartz Rounds and co-chaired the forum. The first author took ethnographic field notes and (unattributed) verbatim quotations from the discussion. Schwartz Center Rounds follow a structured format, including the stipulation that plenty of time is allowed for audience feedback. Importantly, audience feedback is not permitted to be offered from a problem-solving perspective; rather, audience comments and questions are meant to acknowledge the emotional aspects of medical care and neither identify fault nor propose solutions.

As in most Schwartz Center Rounds, nurses were the largest single group represented among the 100 hospital employees present. In anticipation of this majority representation from nursing, the nurse manager introduced the description of the DCC process. She began by recognizing that in difficult cases, it is often challenging for nurses to know how to effectively pass on information, asking, "Who is the team? Who is in charge?" The physician leader continued by adding that physicians are frequently pulled away and miss "windows of opportunity" for consults with other team members as well as discussions with the patient and family, particularly with regard to end-oflife decisions. In many cases, she continued, the physician mindset makes the dignified death a "challenge to our profession." She stressed the importance of frontline personnel such as nurses and hospitalists having both tools and permission to voice those "messy" situations when communication is hostile or when no one is talking.

Immediately prior to opening the floor to audience discussion, the second author briefly described the application of narrative analysis and Burke's pentad to the cases, as well as the oft-noted phenomenon of hospital personnel feeling "in their gut" that something is about to go wrong and simultaneously feeling unable to prevent the unraveling of a difficult case. The audience conversation began with the question, "Does this happen? Do you have this intuition that something is going wrong?" Some of the responses are worth recording here:

\footnotetext{
"We see it. Doctor to doctor. The consult [specialist] who disagrees with the attending [primary care physician] but doesn't communicate directly."

"People are so afraid of stepping on each other's toes - to the detriment of the patient."

"Physicians are not good at giving bad news, so they don't give it."

"Patients who say they don't want anything [heroic measures] are labeled as crazy and we call in psych."

"Many of these situations are not ethical dilemmas-it's about communication."
} 
Relatedly, one of the major initiatives in the hospital network at the time of this Schwartz Center Rounds was an efficiency program modeled after an internationallyrecognized quality improvement process - Toyota Lean. ${ }^{35} \mathrm{~A}$ critical component in the Lean philosophy is that each member of the assembly line is empowered to stop the process - jidoka - or pull the cord. One of the audience members offered this possibility:

At the bedside, anyone should be able to "pull the cord" and call a difficult case mediation that brings everyone together to talk about the case. It needs to be an institutional priority to meet in the next 36 hours.

Because of the nature of Schwartz Center Rounds, the audience responses from which these comments were se- lected were gathered ethnographically rather than through a more formal survey method; however, as facilitators, we were encouraged that the process made sense to this interdisciplinary group of 100 healthcare workers and that they were able to perceive and reflect on its utility in their day-to-day practice.

\section{Discussion}

Through the DCC project, we generated a number of insights into interprofessional clinical communication and difficult cases. The principle benefit we witnessed was the shift in hospital staff members' perspectives from hopelessness and inertia to empowerment and forward movement. The emotional effect of the consultation was like the untangling of a complex knot that had kept the team

Table 1. Summary of narrative elements before and after DCC reframing.

\begin{tabular}{|c|c|c|c|c|}
\hline & Who/Agent & $\begin{array}{l}\text { Where \& } \\
\text { When/ Scene }\end{array}$ & What/Act & How/Agency \\
\hline Case 1 BEFORE & $\begin{array}{l}\text { The patient, obese } \\
\text { woman in her } 30 \mathrm{~s} \text {; } \\
\text { ulcer from staying on } \\
\text { couch after a fall. } \\
\text { Family members } \\
\text { "enabling" and } \\
\text { dissatisfied with care }\end{array}$ & $\begin{array}{l}\text { Medical Surgical } \\
\text { Floor }\end{array}$ & $\begin{array}{l}\text { Hospitalized for many } \\
\text { months; complex and } \\
\text { conflicting } \\
\text { communication with } \\
\text { hospital staff; refusal } \\
\text { to address weight loss } \\
\text { concerns }\end{array}$ & $\begin{array}{l}\text { Manipulative and } \\
\text { demanding patient anc } \\
\text { family; abusive of } \\
\text { hospital staff }\end{array}$ \\
\hline Case 1 AFTER & $\begin{array}{l}\text { Risk Mgmt, Ethics, } \\
\text { Plastics, Internal Med, } \\
\text { Psych }\end{array}$ & $\begin{array}{l}\text { Obese patient with } \\
\text { persistent ulcer }\end{array}$ & $\begin{array}{l}\text { Inconsistent and } \\
\text { indirect } \\
\text { communication from } \\
\text { staff; failure to act; } \\
\text { fragmented daily tasks } \\
\text { w/o an overall } \\
\text { strategy, lack of } \\
\text { medical leadership }\end{array}$ & $\begin{array}{l}\text { Enablement of } \\
\text { dysfunctional } \\
\text { communication; } \\
\text { power without } \\
\text { accountability; } \\
\text { shifting of } \\
\text { responsibility for } \\
\text { patient care (med } \\
\text { service had one week } \\
\text { on and one week off } \\
\text { so there was no } \\
\text { attending to lead) }\end{array}$ \\
\hline
\end{tabular}

Case 2 BEFORE

Case 2 AFTER
48 year old male with stage 4 cancer, diagnosed in the ER after presenting with shortness of breath; no close relationship with a PCP
When given diagnosis and prognosis, stated that he wanted to go home to be with his family; then agreed to be admitted and undergo surgery and "heroic treatment;" never went home, died in surgery

Oncology "took over" the case once consulted - the designated PCP and ED physician unwilling to "overrule" specialist didn't recommend 2nd oncology opinion
Emergency room, then medical floor
Had the right to hear different perspectives on the case; changed his mind and needed to be respected

48 year old father an husband with metastatic cancer physician on call (who became designated as PCP)

Palliative medicine, oncology, ED

Why/Purpose Patient and family need for attention and drama; comfortable with conflict; "codependent" relationships

Keeping the family satisfied with care; Press-Ganey (patient satisfaction survey) worry; unwilling to give up control or compromise with other members of the team; desire to "make everyone happy" without thinking about the long-term health of the patient.

Wanted to believe that there was a chance to survive; gave in to the persuasive power of the oncology consult despite initially stating wishes clearly

Hierarchy disempowering relationship between PCP \& specialist needs of the patient (to die at home) not adhered to - creation of false hope hope

(a)

\footnotetext{
Oncologist perspective = "I gave him a chance to live" and "I did everything I could;" PCP perspective $=$ "professionalism" prevents one physician from contradicting another to the patient
} 
immobilized. The second benefit of the process lay in identifying the systemic habits that reoccurred across the different cases. By identifying these patterns, the team was able to find a positive direction for system-level changes that might in the future prevent the occurrence of a difficult case or speed its resolution. We elaborate on both benefits in the sections that follow.

\section{Reframing a case from hopeless to manageable}

A consequence of the DCC was that the language of the group shifted away from blame and scapegoating (of difficult patient personalities, complicated family members, or "arrogant" consulting physicians) and towards an appreciation for how the organizational system failed to respond optimally to the cases as they unfolded. The reframing process helped group members to perceive aspects of trained incapacity inherent in the culture of this institution and, based on our experiences elsewhere, healthcare institutions in general. We argue that perceiving this trained incapacity is a first step in overcoming it.

According to Burke, ${ }^{36}$ "we can't say anything without the use of terms" (p.50) and terms that populate the discourse of a given context - a hospital system in this case-reveal both conscious and unconscious choices about how to make sense of a situation. For example, the term "adverse event" used to describe anything from a medication error to fatal iatrogenic infection is a choice that serves to both generalize and depersonalize the details of medical mistakes. In Burke's vocabulary, a terministic screen refers to habits of language that serve to repress other options for describing events or phenomena.

As might be predicted, by narrating the case with the patient as the agent, the other components of the story followed suit. Patients (and their families) became problems to be solved, and, consequently, the story reflected a curious absence of agency on the part of the hospital staff, who seemed almost universally bewildered regarding how to change the course of these types of events. Burke $^{27}$ argues that humans pursue "vocabularies that will be faithful reflections of reality. To this end, they must develop vocabularies that are selections of reality. And any selection of reality must, in certain circumstances, function as a deflection of reality." (p.59) Burke does not imply here that language choices are a conscious deflection of reality, only that deflection is the result, and is accomplished through rhetorical choices. Burke $^{36}$ suggests we are "goaded by the spirit of hierarchy" (p.16) or, with regard to the work of healthcare professionals, the promise of order and status. When the promise of modern medical science disappoints - as is apparent with difficult cases - a scapegoat must be identified. "Occupational psychosis" is the term Burke gives to the tendency of members in a given profession to perceive reality in particular ways. The DCC reframing process redirects this tendency to ascribe blame in par- ticular ways in the medical context. As a consequence of narrative reframing, then, perhaps the tendency to scapegoat can be avoided altogether.

The apparent lack of agency of the clinicians providing care was particularly surprising when we considered how several members of the group reported intuitions early in the course of these cases; the phrase "we knew this would not end well" seemed to encapsulate the feeling of both insight and helplessness in the difficult case. In every case we addressed, the members of the interprofessional group turned from a frame that placed responsibility on a distant "other" to a frame in which the hospital system's own exigencies contributed to the poor outcomes. In Case 1, the "manipulative" patient and family members were reframed as individuals who were frustrated by the situation and possibly in need of more consistent guidance and attention by the medical team. In Case 2, the "unrealistic" oncologist who overrode the advice of colleagues and the wishes of the patient was seen in a different light — as a physician who believed he was doing all he could for a patient. An insight into this positive - and ultimately misguided - motive might have provided rhetorical leverage for others to point out that the patient's voice was being silenced in the oncologist's effort to "do all he could." In a mirror image of the oncologist's actions, the lack of intervention by the emergency department staff, family practice physicians, and palliative care team was reviewed in light of the realization that they put the saving of "professional face" ahead of what they knew about the patient's prognosis, what the patient envisioned for his final days, and what they had come to believe was best for the patient.

\section{Recognizing systemic factors in difficult cases}

The DCC process helped to highlight several ways in which a system of care can perpetrate or perpetuate a challenging dynamic among staff, patient, and family members.

\section{Professional communication}

Physicians were not likely to communicate differences of opinion directly to a colleague. Indeed, two physicians writing notes on the same chart might contradict each other, but would not necessarily raise that as an issue for discussion. Healthcare providers might talk to a peer in order to "vent," but would not likely talk to the person with whom there was a communication problem.

Discussing nurses' clinical perceptions, Miller and Hill $^{37}$ report that experienced senior-level nurses employ multiple sense-making mechanisms to enhance clinical judgment, including intuition and gut feelings. Although their research focused specifically on nurses' clinical assessment of patients, we propose that the same instinctive judgments might well be in play when a system of care is in danger of becoming unstable. One implication of our research is that a process like the DCC provides a formal context in which nurses can voice these intuitive concerns 
and positively impact the trajectory and outcomes of care. Members of our interprofessional team described having "gut feelings" early in a case without sharing them. In the words of one of the Schwartz Rounds audience members, this instinct represents a moment of opportunity to "pull the cord." Despite the value of these instincts, habits of professional communication currently prohibit the outward voicing of concern, whether related to instincts about a patient's prognosis or conflicting clinical judgements between colleagues. Physicians, for example, did not make family members aware of differences in professional opinion, possibly engaging in face-saving on behalf of a colleague or themselves. We noted that professional hierarchies among various clinicians exacerbated the prohibitions against speaking up.

\section{Lack of coordination}

Different specialties had different goals of treatment. These differences were especially glaring between the "high end" specialists and the primary care physicians, but there were also differences within specialties regarding goals of treatment. Predictably, the internist/generalist/family doctor wanted to maintain consistency based on what had come to be understood as their patients' wishes. While individual attending physicians may have provided realistic prognoses, when there was regular turnover among attendings to a specific unit and/or abbreviated handoffs, there was a risk of insufficient continuity in the care of patients who fell into the realm of "difficult cases." There was a strong conviction among the interprofessional group that the PCP should be the "quarterback" in the interests of better coordination.

\section{Shifting goals of care}

One pattern we observed through our interaction with the team and in the analysis of the cases was that generalists, whether hospitalists or primary care physicians, were more likely to identify a realistic outcome than were specialists. Generalists tended to see the "big picture" of a given patient, particularly if they were a primary care provider to the patient prior to hospitalization. And yet, the specialist-as-consult had assumed a hierarchically superior role in the hospital and often in the minds of patients, leading to a lack of clarity around goals of care. Certain prognoses were not communicated clearly, and there was a tendency for uncertain prognoses to not be presented as uncertain.

In health systems generally, there is rarely an established practice of laying out a realistic scope of best-case to worst-case scenarios to patients and family members. If anything is left out of the conversation, it is the worstcase scenario. Also, in the difficult cases we encountered when working with the interdisciplinary team, goals of care were often inconsistent, whether between PCP and specialist, or between physician and patient. When goals did change, not everyone was kept in the loop. Members of the interprofessional team conceded that it is the patient's right to "make bad decisions." The DCC process reminds hospital personnel to recognize the patient's and family's needs as more important than the occupational habits that can drive medical decision-making. In turn, family members can be recast as resources who know best the needs of the patient.

McDougall and colleagues ${ }^{30}$ advance the idea of collaborative entanglements to describe how intraprofessional and interprofessional teams negotiate meaning and framing in the desire to learn from each other, despite inconsistent professionally socialized classifications and descriptions. In short, they emphasize that diverse team members must learn to be comfortable with ambiguity. In her study of rapid-response teams, Colvin ${ }^{12}$ employs knotworking as a metaphor to describe medical situations with distributed responsibilities and swiftly changing circumstances that require improvisation. The "knot" is a tightening and loosening of potential or actual clashes in light of that improvisation. As is the case with collaborative entanglements and knotworking, the DCC process reveals what are, at times, negotiated territorial tensions. What the DCC adds is the recognition that members of interdisciplinary teams must be encouraged to break free of the frames that are failing to support effective patient care and speak up when they have misgivings about the way patient care is unfolding.

\section{Future directions}

As compelling as the results of this initial project are, we recognize that the DCC process requires testing in additional clinical environments to be certain of its utility and generalizability. Plans to further test and refine the process involve initiating the DCC with another interprofessional group of inpatient providers. Two additional tests of the process are needed. First, we should analyze a larger population of reframed narratives in another healthcare organizational setting to identify systemic features of communication that exacerbate difficult cases. Second, we need to assess the clinical impact of the DCC on quality of care. Our hope is that engaging in DCC will improve systems of communication to reduce the incidence of difficult cases and help practitioners to "head off" the unraveling of difficult cases by intervening earlier in the case with positive and collaborative communication. As the COVD-19 pandemic continues to challenge healthcare systems and critical care clinicians in particular, we expect that the profile of "difficult cases" will evolve in association with this acute infection and the systemic response to what is being called "long COVID." ${ }^{38}$ Effective communication and collaboration among clinicians will continue to be needed in response to difficult cases, for the good of patients and practitioners alike. 


\section{References}

1. Cissna K. Applied communication research in the $21^{\text {st }}$ century. J App Commun Res 2000;28:169-73.

2. De Oliviera GCB, Alves MR, Ramalho De Oliviera D. Action research as a tool for transformation of the pharmacist's praxis in primary care. Int J Pharm Pharm 2017;9:180-5.

3. Eisenberg E, Baglia J, Pynes J. Transforming emergency medicine through narrative: Qualitative action research at a community hospital. Health Commun 2006;19:197-208.

4. Cheney G. Organizational rhetoric: The practice of criticism. J App Commun Res 1990;18:93-114.

5. Crable RE. Organizational rhetoric as the fourth great system: Theoretical, critical, and pragmatic implications. J App Commun Res 1990;18:115-28.

6. Meisenbach RJ, McMillan JJ. Blurring the boundaries: Historical and future directions in organizational rhetoric. Commun Yearb 2006;30:99-141.

7. Morgenthaler T, Harper CM. Getting rid of "never events" in hospitals. Harvard Bus Rev 2015. Available from: https://hbr. org/2015/10/getting-rid-of-never-events-in-hospitals

8. Dieleman JL, Squires E, Bui AL, et al. Factors associated with increases in US health care spending, 1996-2013. J Amer Med Assoc 2017;318:1668-78.

9. Hajat C, Stein E. The global burden of multiple chronic conditions: A narrative review. Prevent Med Rep 2018;12:284-93.

10. Defenbaugh N, Baglia J, Foster E. Billable (h)ours: Autoethnography, ambivalence, and academic labor in a healthcare organization. In Herrmann A, ed. The Routledge international handbook of organizational autoethnography. New York, NY: Routledge; 2020. pp 191-208.

11. Schot E, Tummers L, Noordegraaf M. Working on working together: A systematic review on how healthcare professionals contribute to interprofessional collaboration. J Interprof Care 2020;34:332-42.

12. Committee on Diagnostic Error in Health Care; Board on Health Care Services; Institute of Medicine; The National Academies of Sciences, Engineering, and Medicine; et al. Improving diagnosis in health care. Washington, DC: National Academies Press; 2015.

12. Colvin J. Knotworking in an emergency response team: Understanding team communication and process. Qual Res Med Healthc 2017;1:128-37.

13. Schmutz J, Meier L, Manser T. How effective is teamwork really? The relationship between teamwork and performance in healthcare teams: A systematic review and meta-analysis. Brit Med J Open 2019;9:1-16.

14. Gawande A. Complications: A surgeon's notes on an imperfect science. New York, NY; 2002.

15. Makary M, Daniel M. Medical error-the third leading cause of death in the US. Brit Med J 2016;353:i2139.

16. Franc,ois P, Lecoanet A, Caporossi A, Dols AM, Seigneurin A, Boussat B. Experience feedback committees: A way of implementing a root cause analysis practice in hospital medical departments. PLoS One 2018;13:e0201067.

17. Weick K, Sutcliffe K. Managing the unexpected: Resilient performance in an age of uncertainty. San Francisco, CA:Jossey-Bass;2007.
18. Worman D, Rock M. Teaching nursing students root-cause readmission analysis. Nurse Educ 2021;46:15-6.

19. Martin-Delgado J, Martínez-García A, Aranaz JM, Valencia-Martín JL, Mira JJ. How much of root cause analysis translates into improved patient safety: A systematic review. Med Princ Pract. Published online May 15, 2020.

20. Hong H, Oh HJ. The effects of patient-centered communication: Exploring the mediating role of trust in healthcare providers. Health Comm 2020;35:502-11.

21. The Joint Commission. Sentinel Event. 2021. Available from: https://www.jointcommission.org/resources/patientsafety-topics/sentinel-event/

22. The Schwartz Center (n.d.). Official Website. https://www. theschwartzcenter.org/programs/schwartz-rounds

23. Charon R. Narrative medicine: Honoring the stories of illness. Oxford, UK: Oxford University Press; 2006.

24. Silverman RE, Baglia J. Communicating pregnancy loss: Narrative as a method for change. New York, NY: Peter Lang Academic Publishing; 2014.

25. Foster E. Physicians' stories: Autoethnography, presence, and rhizomatic inquiry. Int Rev Qual Res 2014;7:290-301.

26. Taylor B. Narrative analysis. In Taylor B, Francis K, eds. Qualitative research in the health sciences. London: Routledge; 2013. pp. 243-265.

27. Burke K. A grammar of motives. Berkeley, CA: University of California Press; 1969.

28. Bareiss W. Space, boundaries, and identification: A dramatistic approach to HIV counter-narratives. Int J Comm Health 2016;9:62-72.

29. Chou C, Hirschmann K, Fortin A, Lichstein P. The impact of a faculty learning community on professional and personal development. Acad Med 2014;89:1051-6.

30. McDougall A, Goldszmidt M, Kinsella EA, et al. Collaboration and entanglement: An actor-network theory analysis of team-based intraprofessional care for patients with heart failure. Soc Sci Med 2016;164:108-17.

31. Goffman E. Frame analysis: An essay on the organization of experience. Cambridge, MA: Harvard University Press; 1974.

32. Lindlof T, Taylor B. Qualitative communication research methods. 2nd ed. Walnut Creek, CA: Sage Publications; 2002.

33. Willis R. The use of composite narratives to present interview findings. Qual Res 2018;19:471-80.

34. Barker R, Cornwell J, Gishen F. Introducing compassion into the education of health care professionals: can Schwartz Rounds help? J Comp Care 2016;3:3.

35. Isfahani HM, Tourani S, Seyedin H. Lean management approach in hospitals: a systematic review. Int J Lean Six Sigma 2019;10:161-88.

36. Burke K. Language as symbolic action: Essays on life, literature, and method. Berkeley, CA: University of California Press; 1966.

37. Miller EM, Hill PD. Intuition in clinical decision making: Differences among practicing nurses. J Holist Nurs 2018;36:318-29.

38. Mehase E. Covid-19: What do we know about "long covid"? BMJ 2020;370:m2815. doi.org/10.1136/bmj.m2815 